\title{
A dynamic hypothesis for developing energy-efficiency technologies in housing industry
}

\author{
Ibrahim A. Motawa*, Phil F. Banfill \\ School of the Built Environment, Heriot-Watt University, Edinburgh, EH14 4AS, UK \\ * Corresponding author. Tel: +44 1314514620, Fax: +44 1314513161, E-mail: i.a.motawa@hw.ac.uk
}

\begin{abstract}
The UK target to significantly reduce $\mathrm{CO}_{2}$ emissions from housing has been challenged by the fact that $80 \%$ of the UK housing stock existing in 2030 has already been built. Energy-efficiency technologies for existing housing are developed in attempt to meet this target, e.g. fabric upgrades, ventilation systems, etc, but the interrelationship between the technical and social aspects of using these technologies is not fully understood. From the household perspective, a clear financial case in addition to other intangible benefits should exist to create high demand for these technologies. On the other hand, many technological interventions are still in the development stage and according to the technology diffusion theory there will be a delay in adopting these technologies on the expected scale. This study will use system dynamics modelling to investigate the relationship between the supply and demand of energy-efficiency technologies for existing housing. A dynamic hypothesis will be set to analyse the interrelationships among the controlling variables of technologies development over a period of time. This paper introduces the main structure of the study and discusses the technique adopted to model the identified dynamic hypothesis.
\end{abstract}

Keywords: Energy-efficiency technologies, System dynamics

\section{Introduction}

The housing industry in the UK is experiencing its transition period from traditional to energy efficient. The call for energy efficient houses has been intensified in the light of the high demand for energy. The growth of energy prices increases the pressure on hous eholders to find solutions to the energy bills, and on the industry to develop more energy efficient technologies for houses. The introduction of UK targets to reduce $\mathrm{CO}_{2}$ emissions has also a great effect on both the householders and developers. In the UK, approximately $26 \%$ of $\mathrm{CO}_{2}$ emissions are attributable to the domestic sector ${ }^{[1]}$. At least $70 \%$ of the UK housing stock that will be present in 2050 have been already constructed before year $2005^{[2]}$. Therefore, modifications to the existing housing are essential to meet the targets of the UK Climate Change Bill. However, it is not only energy efficiency technologies that will achieve the $\mathrm{CO}_{2}$ emissions target, but the changes to occupants' behaviour will also have a great influence to accommodate these modifications.

Despite the growing development in Energy Efficiency technological interventions, the uptake of these technologies is not great enough to show that there is a significant reduction in energy consumption and $\mathrm{CO}_{2}$ emissions. Among the reasons for this market failure might be that the costs and benefits of refurbishment options are often complex to determine ${ }^{[3]}$. Achieving the target of $\mathrm{CO}_{2}$ emissions will require large investments in the stages of energy generation, transmission, conversion and end-use, together with measures to control demand. Oreszczyn and Lowe ${ }^{[4]}$ indicated that this necessitates the need for research to help formulate and evaluate policy, to measure progress, and to help industry to deliver.

\section{Methodology}

A previous study, 'TARBASE', ${ }^{[5]}$, investigated a number of technologies in the field of end use technology, building fabric and energy supply technologies to achieve reductions in $\mathrm{CO}_{2}$ emissions. Three intervention sets were identified with their effect on $\mathrm{CO}_{2}$ emissions 
attributable to two selected dwelling types, namely; 'comprehensive', 'complete', and 'limited' intervention sets. A Whole Life Cost (WLC) approach has been conducted to investigate the cost implications for the uptake of these intervention sets by householders. The study concluded that there is no clear financial case over a 25 year horizon for householders to invest in the proposed interventions. The results also revealed the need for new policy approaches to overcome the financial and non-financial hurdles for a mass uptake of Energy efficiency technologies ${ }^{[6]}$. This paper builds on the results of TARBASE and investigates in a wider context the development and diffusion of energy efficiency technologies for housing. Variables affecting different policies to reduce $\mathrm{CO}_{2}$ emissions such as subsidy, rising energy price, R\&D investment from the industry, etc. are considered. Technology diffusion theory reveals that technological development and implementation includes a long delay to be fully diffused. In addition, effective implementation of technological innovations requires an understanding of the complexity underpinning the process and the inherent uncertainty about the actual performance of low energy housing ${ }^{[4]}$. The adoption of innovative technologies also requires reliable performance indicators to be employed to ascertain the condition of such processes. Models that simulate the implementation of new technologies need to consider the effect of experimentation, iteration and refinement of activities that are reliant on volatile information ${ }^{[7,8]}$. These models should consider that many variables are time dependent and/or carry a high level of uncertainty. It is understood for example that the efficiency of new technologies is expected to rise by further development and experience in use. In addition, it must be stressed that the emissions savings are only realized when behavioural change accompanies the technological deployment.

Different motivational frames might alter the appraisal of costs and benefits related to a specific pro-environmental behaviour. Understanding the needs satisfied by the purchase of an energy efficient technology would allow their costs to be compared to the cost of other purchases satisfying other needs ${ }^{[9]}$. It is more likely that only a part of the family budget currently allocated for household improvements would actually be spent on energy efficiency improvements, even for those informed individuals with strong pro-environmental attitudes. Additionally, there is no financial incentive associated with the investment if reduction in utility expenditure (at current energy process) is taken as the sole benefit. The deployment of deep cut intervention sets are likely to result in other benefits, such as improved comfort and increased asset value of the property. It is feasible that when all benefits are aggregated, financial incentives will appear for householders and this needs to be explored further ${ }^{[5,9]}$.

In conclusion, the emissions reduction targets required to address the climate change agenda are only likely to be met through a combination of demand and supply side interventions. Identifying technological solutions for achieving a reduction in UK domestic dwellings is complex. Assumptions have to be made regarding for instance construction, occupancy and occupant behaviour in order to define the baseline for assessment of technological interventions which themselves are often interdependent. This would suggest that stressing the ethical or environmental appeal of an energy saving technology will only have limited effect if the technology is perceived by the consumer as having a high capital cost. In response to the challenge posed by this complexity, a System Dynamics (SD) based model is proposed in this research. It can investigate policies that affect the development and diffusion of energy efficiency technologies related to the housing industry during its transition period, considering both the demand and supply sides. SD modelling can identify the causal structure underlying the behaviour of complex systems, simulate the behaviour of time dependent variables and assess the usefulness of different energy policies such as energy tax and R\&D subsidy for diffusing energy efficiency technologies. 
SD modelling involves the following steps ${ }^{[10]}$ :

1. Articulating the problem to be addressed

2. Formulating a dynamic hypothesis or theory about the causes of the problem

3. Formulating a simulation model to test the dynamic hypothesis

4. Testing the model output to satisfy the purpose

5. Designing and evaluating policies for improvement

Based on the relevant literature and data available from TARBASE, the proposed SD model was developed as a hypothetical model. This paper discusses the first two steps of the model development. Further development, requiring additional data, will build a comprehensive SD model.

\subsection{Problem Articulation}

The problem in hand is not only about the typical process of technology diffusion, but also about the effect of the pressure to reduce $\mathrm{CO}_{2}$ emissions and the social and economical implications of using these technologies. Therefore, this step in modelling will identify the major controlling variables of technology diffusion and the effect of using these technologies on $\mathrm{CO}_{2}$ emissions. In addition, the reference mode of the system behaviour will be identified. Reference mode is the graphical representation of the system behaviour over a period of time. This can be based on historical or pre-defined/required behaviour. The optimum behaviour of the system occurs if the pattern of the demand for house upgrading follows the same pattern of the diffusion of the technological intervention sets. Therefore, the technology diffusion theory will help identifying the reference mode of the demand for house upgrading. The time period assumed for the study is to 2050, when the $\mathrm{CO}_{2}$ emissions reduction target is set.

\subsubsection{Technology Diffusion Theory}

Diffusion process is the methodology of adopting an innovation by members of a certain community. Rogers ${ }^{[11]}$ categorizes the five stages of the diffusion of innovations as: knowledge (awareness), persuasion (interest), decision (evaluation), implementation (trial), and confirmation (adoption). Over the time of the diffusion process, new individuals adopt the innovation while others might reject it. Four factors were identified that influence adoption of an innovation, namely: 1) the type and need for innovation, 2) the communication channels used to spread information, 3) time period of diffusion, and 4) the nature of the community to whom innovation is introduced. Technology adoption rate always follows an S-curve that represents the length of time required for a certain percentage of community members to adopt the technology ${ }^{[11]}$, as shown in Fig. 1. There are categories of adopters: innovators, early adopters, early majority, late majority, and laggards. This pattern of technology adoption will be used for the purpose of modelling as "reference mode of diffusion", which for this research will be the reference mode of "demand for house upgrading". The demand for house upgrading will be investigated from the perspective of householders, industry, and government. Individuals usually adopt an innovation if it has some attributes, namely: (1) the innovation has some relative advantage over an existing one, (2) the innovation is compatible with existing values and practices, (3) the innovation is not too complex, (4) the innovation has trialability (i.e. can be tested for a limited time without adoption), (5) the innovation offers observable results.

Various models have been developed in order to simulate the typical diffusion of technological innovations. For example, Veneris ${ }^{[12]}$ developed a SD model which takes into account various diffusion patterns modelled via differential equations. The model did not consider that technology development is dynamic as there is always development or 
improvement over the time of diffusion all along the S-curve. Therefore, the S-curve is actually made up of a series of S-curves of different sections of a population adopting different versions of technologies. It did not also simulate the effect of the pressure to reduce $\mathrm{CO}_{2}$ emissions and the social and economical implications of using these technologies

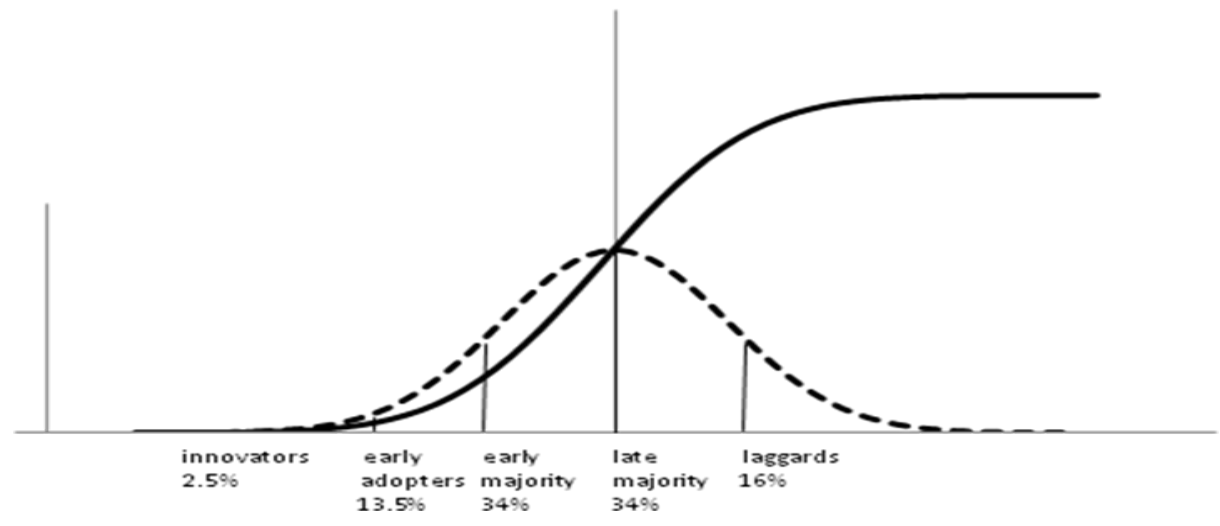

Fig. 1. Innovation adoption rate (Rogers $\left.{ }^{[11]}\right)$

The other main reference mode required for this model is for the rate of $\mathrm{CO}_{2}$ emissions reduction. The target set for the year 2050 will be used as a guidance reference mode in this model (further data is required to refine this mode in a more accurate rate). Fig. 2 suggests that the linear emissions reduction rate since 1970 was $7.5 \mathrm{Mt}\left(\mathrm{CO}_{2}\right) /$ decade. This would achieve a $60 \%$ reduction in $\mathrm{CO}_{2}$ emissions from UK buildings by 2050 . To achieve the $80 \%$ reduction adopted by the UK government in 2009, a faster rate of reduction (around 10 $\mathrm{Mt}\left(\mathrm{CO}_{2}\right) /$ decade $)$ might be needed ${ }^{[4]}$.

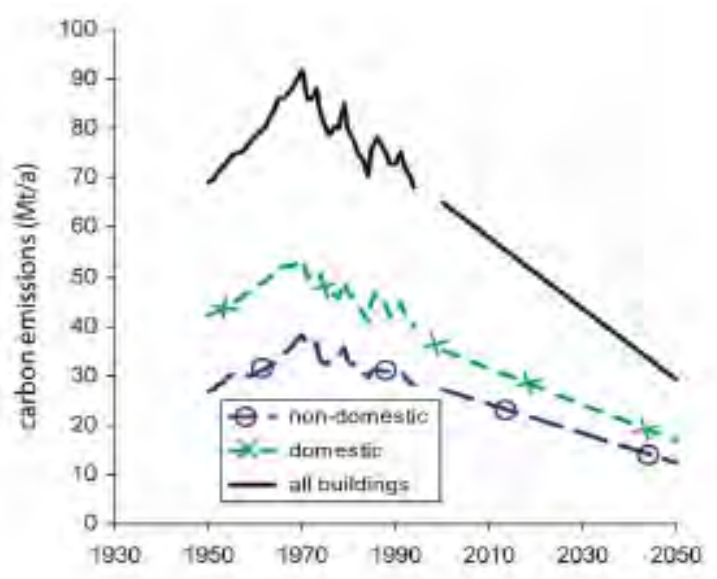

Fig. 2. Domestic and non-domestic carbon emissions to 1994 with trajectories to $40 \%$ of 1990 emissions in 2050 (reported in Oreszczyn and Lowe ${ }^{[4]}$ )

\subsection{Formulation of the dynamic hypothesis}

A dynamic hypothesis is set to explain the behaviour of the system and the relationships among its variables that develop its reference mode. Four mapping tools were used to develop this hypothesis, which are: Subsystem diagram, Model boundary chart, Causal loop diagrams, and Stock and flow maps. As this paper aims only to introduce the hypothetical model, the Stock and flow maps will not be presented. 


\subsubsection{Subsystem diagram}

Fig. 3 classifies the architecture of the studied system into a number of subsystems. Each subsystem is mainly controlled by a certain variable, as illustrated by the variable name in each box of Fig. 3. The main control variables of each subsystem and the interactions between each other will be identified on the causal loop diagrams. For example, the actual proportion of dwellings using the intervention sets is used to measure technology diffusion. The other identified variables influence this measurement, namely; Rate of technology change, Unit energy consumption, $\mathrm{R} \& \mathrm{D}$ Investment, and $\mathrm{CO}_{2}$ emissions. A number of feedback loops have been identified that control the subsystems behaviour, namely; Technology change loop, R \& D loop, Consumption loop, and Emission loop. These loops will be studied and simulated to show how the system behaves under different conditions and policies.

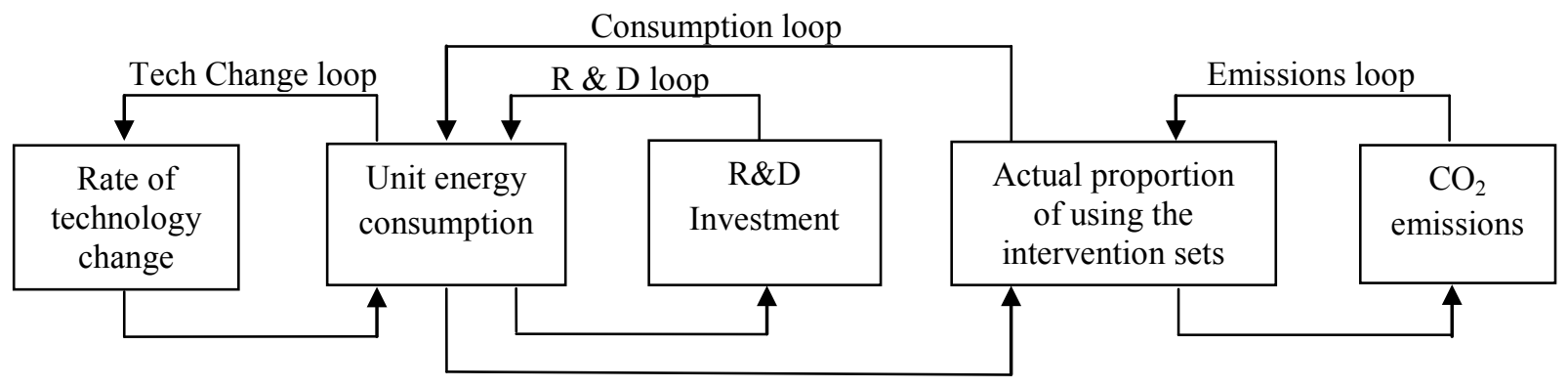

Fig. 3. Model sub-systems

\subsubsection{Model boundary chart}

The chart identifies the scope of the model by classifying the variables into endogenous, exogenous, and excluded variables, as shown in Table 1. This classification is essential to identify the model boundary in terms of the type of each variable and the relationships among variables.

The current version of the model excludes the interest rate on saving/investing the cost of house upgrade assuming that they will balance the effect of inflation on all expenses. The variables considered for the selection of intervention sets are: energy price (economical factor) and $\mathrm{CO}_{2}$ emission (environmental factor) and $\mathrm{R} \& \mathrm{D}$ investment as financial support. Other variables influencing technological developments such as market impact or other new ways of house upgrading are excluded. The exogenous variables have great impact on the endogenous structure but their behaviour will be included from one single relationship for the purpose of this model.

\subsubsection{Main Causal Loop Diagram (CLD)}

For each of the above subsystems, a CLD is developed. The main CLD for the adopted model (Fig. 4) shows how the variables are related to each other. The resulting reinforcing loops and balancing loops will be discussed next. 
Table 1. Model boundary chart

Endogenous Exogenous $\quad$ Excluded

- Actual use of intervention sets

- Energy tax

- Other cost of house upgrade until energy need

- Effect of technology on unit energy consumption

- Average energy production price

- Average unit energy consumption

- Indicated house upgrade demand

- Average energy demand

- R\& D investment

- Effect of cost on house upgrade

- Indicated unit energy cost

- House value

- Industry revenue

- Technology change rate

- Actual energy consumption

- $\mathrm{CO}_{2}$ emissions
- Reference energy price

- Government subsidy

- Intangible effects

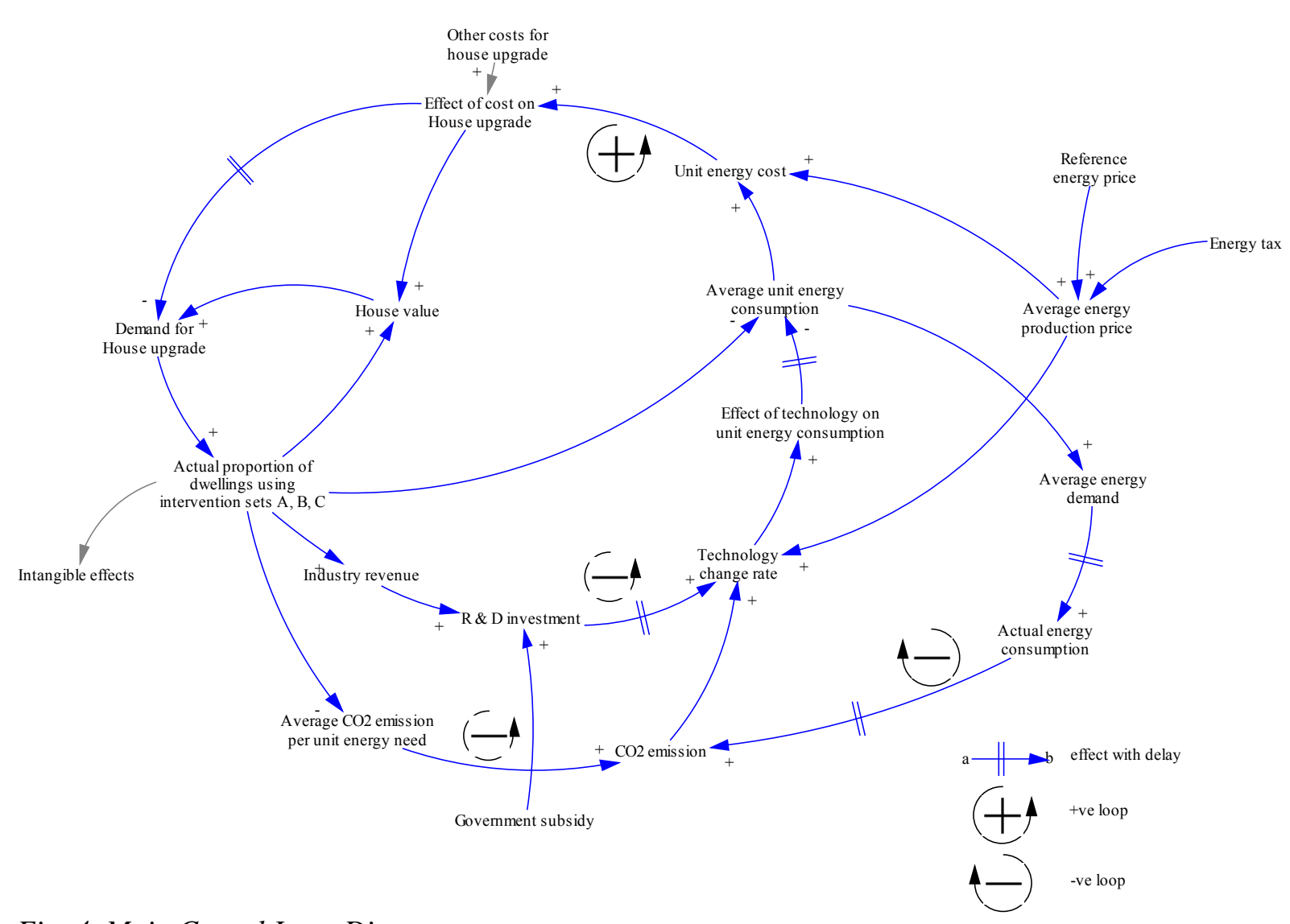

Fig. 4. Main Causal Loop Diagram

- Inflation rate

- Interest rate

- Other factors to influence selection of sets

- Effect of competition on technology change rate

\section{Results}

The model variables and the causal relationships among them are defined. Positive signs are given to parallel relationships, while negative signs are for inverse relationships. The structure 
of system variables and relationships may create feedback loops. The polarity of a feedback loop (i.e., positive or negative) is identified by summing the polarities of the relationships among its variables. Loops with an odd number of negative relationships are negative. Loops with an even number of negative relationships are positive. Variables within positive loops will continue to increase indefinitely, therefore positive loops are self-reinforcing. Variables within negative loops will stabilize over time, therefore negative loops are self-balancing. Feedback loop structures, once identified, are translated into stock-flow diagrams to enable the SD simulation. The simulation part is beyond the scope of this paper. Clearly, the degree of details at which a CLD is defined strongly influences the success of this approach, and considerable care should be taken to develop it right.

\subsection{Consumption loop (+ve loop)}

Improving average unit energy consumption by increasing the actual proportion of using intervention sets; [Average unit energy consumption - unit energy cost - Effect of cost on house upgrade - Demand for house upgrade - Actual proportion of using intervention sets A,B,C - Average unit energy consumption]. Energy efficiency improvement can be measured by the reduction in the Average unit energy consumption, which reduces the unit energy cost and subsequently the effect of cost on hous e upgrade, which leads to an increase in the demand for house upgrade. High demand for house upgrading will increase the use of intervention sets, which in turn decreases the average unit energy consumption.

\section{2. $R \& D$ loop (-ve loop)}

R\&D Investment results in reducing the unit energy consumption; [Average unit energy consumption - unit energy cost - Effect of cost on house upgrade - House value - Demand for house upgrade - Actual proportion of using intervention sets A,B,C - Industry revenue - R $\&$ D investment - Technology change rate - Effect of technology on unit energy consumption - Average unit energy consumption]. R\&D investment is increased by input from industry and government sources. The higher ratio of industry revenue from selling more intervention sets, the higher dedicated funds for R\&D. This will lead to more advanced technologies that reduce the average unit consumption.

\subsection{Emissions loop (-ve loop)}

The increasing use of the technology intervention sets will reduce $\mathrm{CO}_{2}$ emissions; [Average unit energy consumption - unit energy cost - Effect of cost on house upgrade - Demand for house upgrade - Actual proportion of using intervention sets $\mathrm{A}, \mathrm{B}, \mathrm{C}-$ average $\mathrm{CO}_{2}$ emissions per unit energy need - $\mathrm{CO}_{2}$ emissions - Technology change rate - Effect of technology on unit energy consumption - Average unit energy consumption].

\subsection{Technology change loop (-ve loop)}

While the increase in the Average unit energy consumption might increase the actual energy consumption and the $\mathrm{CO}_{2}$ emissions, but this in turn will accelerate the rate of technology change; [Average unit energy consumption - Average energy demand - Actual energy consumption $-\mathrm{CO}_{2}$ emissions - Technology change rate - Effect of technology on uni $\mathrm{t}$ energy consumption - Average unit energy consumption].

The double lines shown on some links indicate the expected delays in realising a significant effect of one variable on the other, such as effect of technology development on application (the average unit energy consumption). These delay relationships are important to understand the behaviour of the system and the estimated time to measure the effect of the technological intervention sets during the transition period. There are a number of variables (on the gray 
arrows) which are modelled as exogenous inputs or policy variables based either on $\mathrm{d}$ ata series of reality or using some reasonable assumptions. By definition, these exogenous variables may influence the model behaviour but are not part of the main causal loops.

\section{Conclusions}

The diffusion of energy efficiency technologies for housing, considering both the demand and supply sides, has been investigated in this paper. Modelling the diffusion process using SD principles shows that various relationships within the process are developed that can help achieving the target of $\mathrm{CO}_{2}$ emissions. The developed CLD with negative feedback loop will have a systemic resistance to undesirable outcomes within the system. However, a positive feedback loop will cause instability to the system performance. Therefore, when implementing changes for variables in a positive feedback loop, all other variables should be monitored to ensure that undesirable outcomes are controlled. Further analysis is required to validate the system behaviour against the identified reference modes.

\section{References}

[1] DEFRA, e-Digest of Environmental Statistics, online available from (http:// www.defra.gov.uk/environment/statistics/index.htm), 2009.

[2] Z. Zavody, Pathway to zero-carbon homes. In, European Council for an Energy Efficient Economy (eceee) 2007 Summer Study, Côte d"eAzur, France, 4-9 June 2007.

[3] Sustainable Construction Task Force, Making the most of our built environment, DTI, 2004.

[4] T. Oreszczyn and R. Lowe, Challenges for energy and buildings research: objectives, methods and funding mechanisms, Journal of Building Research \& Information, Volume 38 (1), 2010, pages $107-122$

[5] A. Peacock, P. Banfill, M. Newborough, D. Kane, S. Turan, D. Jenkins, M. Ahadzi, G. Bowles, P. Eames, H. Singh, T. Jackson, and A. Berry, Reducing $\mathrm{CO}_{2}$ emissions through refurbishment of UK housing. In, European Council for an Energy Efficient Economy (eceee) 2007 Summer Study, Côte deeAzur, France 4-9 June 2007.

[6] G. Pellegrini-Masini, G. Bowles, A. Peacock, M. Ahadzi, P. Banfil, Whole life costing of domestic energy demand reduction technologies: householder perspectives. Construction Management and Economics, Vol 28 (3), 2010, pages 217 - 229

[7] I. Motawa, A. Price, and W. Sher, A Fuzzy approach for evaluating the iterated implementation of innovations in construction, International Journal of IT in Architecture, Engineering and Construction, Vol. 1(2), 2003, pp 105-118.

[8] I. Motawa, A. Price, and W. Sher, Modelling the implementation of technological innovations in construction, International Journal of Computer Applications in Technology: Special Issue on Interoperability for SME-based environments, Vol. 20 (3), 2004, pp 78-89.

[9] G. Pellegrini-Masini, The carbon-saving behaviour of residential households. In: Futures of Cities 51 ${ }^{\text {st }}$ IFHP World Congress, Copenhagen, 2007.

[10]J. Sterman, Business dynamics: systems thinking and modelling for a complex world. McGraw-Hill, 2000.

[11]E. Rogers, Diffusion of innovations. New York: Free Press ISBN 0029266505, 1995.

[12] Y. Veneris, Modelling the transition from the Industrial to the Informational Revolution, Environment and Planning, 22 (3), 1990, pp. 399-416. 